\title{
Termination of Dietary Treatment of Phenylketonuria
}

\author{
FREDERICK P. HUDSON \\ From Alder Hey Children's Hospital, Liverpool
}

If a low phenylalanine diet is started within a few weeks of birth, the severe mental retardation found in most untreated phenylketonurics may be averted. Is it too optimistic to hope that if the brain is spared the biochemical abnormalities of phenylketonuria by careful treatment during the first four or five years of life it will continue to function normally even though the abnormalities are allowed to return? This problem is important and urgently needs an answer, for it is not easy to keep a child of school age on a strict diet, especially when other children at home are enjoying normal food. This article considers only phenylketonuric children who, after receiving treatment, have attained normal or near normal intelligence; the resumption of normal diet by a child who already has brain damage may pose different problems. Four children under treatment at Alder Hey Children's Hospital were permitted to resume normal diet when it became clear that a strict diet could no longer be maintained at home, and to confine them to an institution for continued treatment was not considered justifiable.

\section{Case Reports}

Case 1. Anthony started treatment in 1957 at the age of $3 \frac{1}{2}$ weeks. During the first four years of treatment his serum phenylalanine level ranged from $0.5 \mathrm{mg}$. to $10.1 \mathrm{mg}$. $/ 100 \mathrm{ml}$. (average $3.5 \mathrm{mg}$.); in his fifth year he helped himself to forbidden food at home and the level was never below $9.5 \mathrm{mg} . / 100 \mathrm{ml}$. When he started school at the age of 5 years he took forbidden food regularly, his serum phenylalanine was often above $20 \mathrm{mg}$. $/ 100 \mathrm{ml}$. and phenylketones were present in the urine. The expensive low phenylalanine diet was officially withdrawn when he was 5 years 3 months. On development and intelligence testing he achieved the following scores: at age 6 months, 107; 1 year 7 months, $84 ; 2$ years 4 months, $82 ; 3$ years, 73 (specifically retarded in verbal development); 4 years 2 months, 76 ; 6 years, 68 (Wechsler Intelligence Scale for Children (WISC), verbal 65, performance 78); 7 years, 79; 8 years, 73 (WISC, V.76, P.75); 9 years, 88 (V.94, P.85). In school his behaviour and rapport with other children

Received July 1, 1966. were normal. At the chronological age 8 years 11 months his arithmetic age was $7 \frac{1}{2}$ and his reading age 7 years. Five EEG recordings between the ages of 1 and 8 years were normal.

Case 2. Mark (Anthony's brother) started treatment when 8 days old. In the first year the serum phenylalanine level ranged from 0.5 to $7.1 \mathrm{mg} . / 100 \mathrm{ml}$. (average $2.8 \mathrm{mg}$.), in the second year the average was $8 \mathrm{mg}$., and in the third year $10 \mathrm{mg} . / 100 \mathrm{ml}$. His mother, always convinced that Mark was much brighter than Anthony, was neither strict about treatment nor regular in outpatient attendance, and she decided to give him normal diet from the age of 2 years 9 months. When tested at 20 months his over-all score on the Ruth Griffiths scale was 70, with a good performance on locomotor tests and a poor hearing-speech score. At 4 years 6 months his IQ was 75 (Merrill-Palmer) and 73 (WISC, V.76, P.75). The first EEG recording at the age of 22 months was 'grossly abnormal, part of the record bordering on hypsarrhythmia' (Dr. J. R. Roberts); in spite of this alarming report, the child appeared quite normal and experienced no fits or myoclonic spasms, so no anticonvulsant therapy was given. The next two records showed progressive improvement and at 4 years 8 months the recording was quite normal.

Comment. These two brothers have shown no serious deterioration after four years and three years on a normal diet. Anthony has been able to keep his place in a normal school and his verbal score on the Wechsler Intelligence Scale for Children has improved. It has not been possible to test Mark often enough to obtain a true picture of his IQ but the earlier resumption of normal diet may have caused a slight fall, though to the lay observer his behaviour is quite normal and the real test will come when he enters school. It is curious that his EEG improved when his biochemical abnormality returned. An older brother who is not phenylketonuric went through school in the $\mathrm{C}$ stream and according to his headmaster, 'he displayed no great interest in school work'.

Case 3. Brenda started treatment when 10 days old. For four years her serum phenylalanine was satisfactory with an average reading of $3-4 \mathrm{mg} . / 100 \mathrm{ml}$., but soon after starting school she broke the diet so frequently that treatment was abandoned at the age of $5 \frac{1}{2}$ years. Her IQ has been consistently in the 75-85 range: age 1 year, 83; 


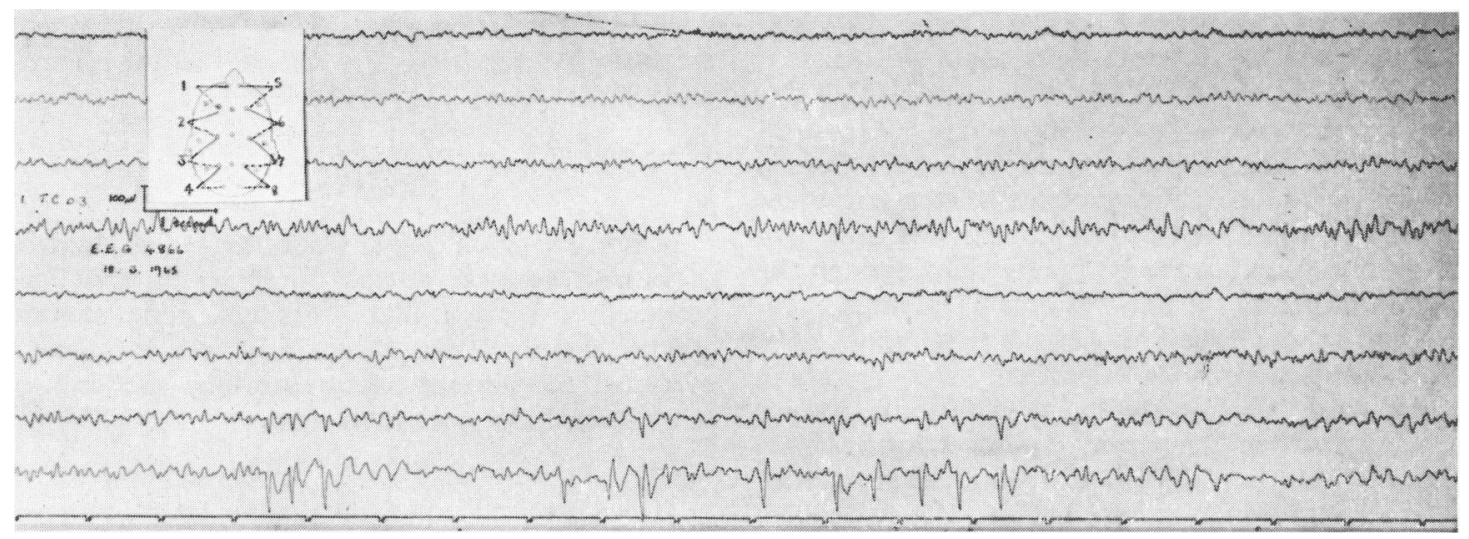

FIG.-EEG (Case 4) shows an irritable spike focus over the left occipital pole, after a normal diet was resumed.

2 years, 80 (Ruth Griffiths scale); 3 years, $83-89$ (MerrillPalmer); age $4 \frac{3}{4}$ years, 100 (Merrill-Palmer); $5 \frac{3}{4}$ years, $79-85$; 63 years, 75 (WISC V.86, P.68); 8 years, 80 (Stanford Binet form L-M). Her EEG records at the age of 4, 5, and 6 years have been within normal limits and no deterioration has followed the resumption of normal diet. She attends a normal school and mixes well with other children, but is in the lowest scholastic group for her age.

Brenda has three sibs: a sister aged 13 who is phenylketonuric (IQ 46, WISC) another sister aged 10, not phenylketonuric (serum phenylalanine normal), IQ 63 (WISC), and a brother aged 9, not phenylketonuric, IQ 104 (WISC), but his school attainments are well below this level.

Case 4. Janet was 14 months old when phenylketonuria was diagnosed. She was then unable to walk without support, she made no effort to communicate, she was hyperkinetic and irritable, and she displayed no interest in any form of toy; her IQ was probably 50-55 but formal testing was not done. In the first four years of treatment the average serum phenylalanine level was $6.0 \mathrm{mg}$. $/ 100 \mathrm{ml}$., but in the next year it rose to $15 \mathrm{mg}$. Treatment was stopped at the age of 6 years 4 months. Formal psychological testing gave the following results: age $2 \frac{1}{2}$ years, 93 (Merrill-Palmer); 4 years 3 months,

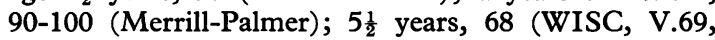

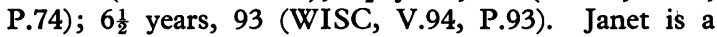
timid child, but quiet, well-mannered, and friendly. The low IQ at age $5 \frac{1}{2}$ years may have been due to lack of co-operation with an unfamiliar psychologist. She finds difficulty with school lessons and at chronological age 7 years 3 months her reading age was $4 \frac{1}{2}$ and arithmetic age $5 \frac{1}{4}$ years. Janet's EEG was normal at the ages of 4 and 5 , while she was receiving treatment, but soon after resuming normal diet an irritable spike focus was recorded over the left occipital pole and has been present in four out of five recordings (Fig.). If this were due solely to the biochemical abnormality one would have expected a generalized dysrhythmia rather than an isolated irritable focus. She shows no abnormal clinical signs and has not had a fit but is now receiving anticonvulsant therapy. Janet comes from a good home and has intelligent and co-operative parents. A sister aged 1 is not phenylketonuric and is developing normally.

\section{Discussion}

There is some evidence to suggest that a high concentration of phenylalanine or its metabolites may damage the brain of the older child or the young adult. An atypical phenylketonuric girl who had the good fortune to develop normally though not receiving treatment experienced her first convulsion at the age of 9 years and then deteriorated a little in intelligence (Woolf, Ounsted, Lee, Humphrey, Cheshire, and Steed, 1961). Crome (1962) found changes of leucodystrophy in the brains of some phenylketonuric patients dying in late adolescence. Mentally retarded phenylketonuric children who have improved on treatment have sometimes deteriorated after normal diet has been resumed, but here the problem of the patient who has sustained brain damage may differ from those who have received early treatment.

Horner, Streamer, Alejandrino, Reed, and Ibbott (1962) reported three children who returned to normal diet when about 4 years old, and after periods of observation ranging from two months to two years none showed deterioration in intelligence. Murphy (1963) also saw no deterioration in two children who took normal diet from the ages of 4 years and 2 months, and 2 years 10 months. Vanderman (1963) observed the effects of stopping treatment in two children, one of whom did not start the diet until the age of 19 weeks and continued only until 2 years 10 months; this child was at all times hyperactive and difficult but evidently did not deteriorate after two years on normal diet. The 
other patient maintained a normal IQ, though he too was hyperactive. Koch (1964) treated a child from the age of 2 years (IQ 68) for two years (IQ 81-87), and by the age of 6 years 10 months the IQ was 88 though the EEG showed multiple seizure bursts. Hsia (1966) allowed four patients to stop treatment at ages ranging from 60 to 72 months, and there was no significant fall in the IQ in any child, though the follow-up period for one was only 11 months.

None of the four children in this report have shown any serious deterioration since resuming normal diet, but considering the life span that we hope awaits them the period of observation has been short. Records of EEG and regular assessment of IQ provide valuable information, but it is also important to study the learning ability, attention span, personality, and reaction to situations of stress. Knowledge of the family and the child's environment are also important. Will these children grow up to take a useful place socially and economically in the society in which they live?

Slight dietary relaxation from the age of 5 or 7 years, allowing a serum phenylalanine level of 10-15 $\mathrm{mg} . / 100 \mathrm{ml}$. but keeping the urine free from phenylketones, may prove to be a useful solution. This approach may have helped to improve the EEG recording of one patient (Koch, 1964), and its value is being studied by $\mathrm{H}$. Bickel (personal communication, 1965). In some homes, however, partial restriction could well prove as irksome and impracticable as the full dietary régime. Until detailed information about many more children is available it seems wise to continue the low phenylalanine diet for as long as possible.

\section{Summary}

Details are given of four phenylketonuric children of normal or near normal intelligence who have resumed a normal diet. Though none showed serious deterioration, there is as yet insufficient evidence to warrant recommending the end of treatment at any particular age.

The author is grateful to the children for allowing him to observe experiments he would not have dared to initiate, and also expresses thanks to the many people who have assisted in the treatment and investigation.

\section{REFERENCES}

Crome, L. (1962). The association of phenylketonuria with leucodystrophy. $\mathcal{f}$. Neurol. Neurosurg. Psychiat., 25, 149.

Horner, F. A., Streamer, C. W., Alejandrino, L. L., Reed, L. H., and Ibbott, F. (1962). Termination of dietary treatment of phenylketonuria. New Engl. F. Med., 266, 79.

Hsia, D. Y-Y (1966). Phenylketonuria: A study of human biochemical genetics. Pediatrics, 38, 173.

Koch, R. (1964). Letter to Dr. Vanderman. (On his paper below.) Amer. F. Dis. Child., 107, 537.

Murphy, D. (1963). Termination of dietary treatment of phenylketonuria. Irish f. med. Sci., 355.

Vanderman, P. R. (1963). Termination of dietary treatment for phenylketonuria. Amer. F. Dis. Child., 106, 492.

Woolf, L. I., Ounsted, C., Lee, D., Humphrey, M., Cheshire, N. M., and Steed, G. R. (1961). Atypical phenylketonuria in sisters with normal offspring. Lancet, 2, 464. 